\title{
A systemic method for evaluating the potential impacts of floods on network infrastructures
}

\author{
J. Eleutério ${ }^{1,2}$, C. Hattemer ${ }^{1}$, and A. Rozan ${ }^{1}$ \\ ${ }^{1}$ Laboratory of Territorial Water and Environment Management (UMR GESTE), ENGEES/IRSTEA, Strasbourg, France \\ ${ }^{2}$ Institute of Fluid and Solid Mechanics (SRE 3240 IMFS), University of Strasbourg/ENGEES/CNRS/INSA, \\ Strasbourg, France
}

Correspondence to: J. Eleutério (julian.eleuterio@gmail.com)

Received: 28 February 2012 - Published in Nat. Hazards Earth Syst. Sci. Discuss.: Revised: 4 September 2012 - Accepted: 13 February 2013 - Published: 18 April 2013

\begin{abstract}
Understanding network infrastructures and their operation under exceptional circumstances is fundamental for dealing with flood risks and improving the resilience of a territory. This work presents a method for evaluating potential network infrastructure dysfunctions and damage in cases of flooding. In contrast to existing approaches, this method analyses network infrastructures on an elementary scale, by considering networks as a group of elements with specific functions and individual vulnerabilities. Our analysis places assets at the centre of the evaluation process, resulting in the construction of damage-dysfunction matrices based on expert interviews. These matrices permit summarising the different vulnerabilities of network infrastructures, describing how the different components are linked to each other and how they can disrupt the operation of the network. They also identify the actions and resources needed to restore the system to operational status following damage and dysfunctions, an essential point when dealing with the question of resilience. The method promotes multi-network analyses and is illustrated by a French case study. Sixty network experts were interviewed during the analysis of the following networks: drinking water supply, waste water, public lighting, gas distribution and electricity supply.
\end{abstract}

\section{Introduction}

Networks are crucial structural elements in urban areas that provide different services and ensure the transport of people and goods (Hubert and Ledoux, 1999). We generally distinguish two types of network: transport networks and technical networks. Transport network infrastructures ensure the transportation of people and goods, such as roads and railways. Technical network infrastructures ensure the production/processing and/or distribution/collection of services/resources, for example, electricity, gas, information, water and wastewater. Network infrastructures are necessary for ensuring that the general objective of the network is reached. They have the fundamental characteristics of systems, i.e. they group elements dynamically correlated to each other and organised as a function of an objective (Narbonne, 2005). This general objective can be categorized into specific missions (Petit, 2009). For example, the extraction of water resources, water treatment, water transportation and delivery to end-users are the missions of the water network. These missions are carried out through several infrastructures, i.e. components composed of different installations and technical apparatus, which have specific functions within the network itself. For example, inside power networks, these components can be voltage transformers, electric cables and individual electric boxes fulfilling different functions. Understanding the global structure of the network is essential for identifying the functions of the different network components and technical apparatus and knowing how they are connected to each other. These items of equipment together make it possible to achieve the general objective of the network, by enabling the operation of the company providing the resources and services necessary for socioeconomic activities (Blancher, 1998).

Network infrastructures have received particular attention in terms of security (Petit, 2009). The increasing dependence of people and the economy on the services offered 
by network infrastructures places them at the centre of the functioning of contemporary society. The efficient operation of networks during crisis periods and their capacity to return to normal operation is fundamental to the society dependent on them. Several works have highlighted the need for better understanding of the capacity of networks to ensure their functions (Bouchon, 2005; Røstum et al., 2008; Petit, 2009). The emergence of the concepts of critical infrastructures and lifelines and their development over the last few decades highlight the global interest in the resilience of networks regarding a wide variety of risks, such as terrorism, financial risks and natural hazards (Adam, 2007; Popescu and Simion, 2011; Robert et al., 2003b; Utne et al., 2010).

Floods are the most destructive natural hazard worldwide and the damage they cause is increasing over time (Messner et al., 2007; Jonkman, 2005). The evaluation of potential flood damage is a widely accepted procedure for studying the vulnerability of systems in view to aiding the decisionmaking processes (Merz et al., 2010; Smith, 1994; White, 1945, 1964). Flood damage is generally classified into four categories according to the damage process, i.e. direct or indirect damage, and to whether or not they can be evaluated in monetary value, i.e. tangible or intangible damage (Merz et al., 2010). In the context of network infrastructures, we expand this classification in order to distinguish internal from external damage. On the one hand, internal damage comprises the impacts of floods on the network itself. Such damage includes direct damage to the infrastructure and the indirect dysfunctions inside the network environment. For example, damage to a power transformer station can lead to the disruption of several components of the power-supply network. External damage, on the other hand, comprises the indirect impacts on the environment of the disruption of networks that depends on the resources and services offered by them (Blancher, 1998; Robert et al., 2003b; Røstum et al., 2008; Petit, 2009). For example, during the Var floods of June 2010 in France, 200000 houses suffered from an electricity outage lasting about three days, due to the disruption of the network. During the same event, a railway between the cities of Nice and Toulon stopped working for four days and several roads and bridges were destroyed ${ }^{1}$.

The great majority of existing methods focus on the evaluation of external indirect damage to networks. These include large-scale models dealing with the indirect economic losses of natural hazards (Crowther et al., 2007; Hallegatte, 2008; Henriet et al., 2012), methods to evaluate damage caused by the disruption of transport, wastewater and electricity networks (Penning-Rowsell et al., 2005), damage through the loss of accessibility to a territory (Demoraes, 2009; Demoraes and D'Ercole, 2009), by the disruption of the water system (Hardy, 2009), and by the interruption of gas distribution (Bouchon, 2009). Regarding internal direct and indirect damage to infrastructures, few data and no

\footnotetext{
${ }^{1}$ French National press information.
}

well-established models exist (Merz et al., 2010). PenningRowsell et al. (2005) recommended using the depth-damage approach for assessing direct damage to network infrastructures; however, no standard data are available. Although several mathematical models can be used for evaluating direct and indirect damage to networks (Dutta et al., 2001, 2003; Jonkman et al., 2008), they are designed for general use and are applicable to all types of networks without taking into account high levels of detail. Indeed, very few methods have been developed for forecasting flood damage to networks (Parker et al., 1987; Jonkman et al., 2008; Penning-Rowsell et al., 2005; Dawson et al., 2011). In addition, the few methods that do exist generally adopt large-scale analyses that ignore the functional aspect of the networks themselves.

In France, the studies analysing damage to networks have mainly focused on investigating previous real damage (CEPRI, 2008). The majority of them have evaluated damage to road infrastructures and only a few have analysed previous damage to multiple networks (MEDD, 2005a, b; S.I.E.E., 2005; Ecodécision, 2006). Feedback from previous flood events shows that internal damage to networks represent a large percentage of total direct damage caused by floods in France (Lefrou, 2000; Huet, 2003; MEDD, 2005b; Ecodécision, 2006; Vinet, 2003). These studies were also limited to evaluating damage over large scales, ignoring the complexity of the internal dysfunctions of networks. The only study that took into account the technical dysfunctions of networks in an ex ante approach was that by Desgranges (1999), which proposed flood scenarios for network managers regarding the Seine and Marne rivers. D4E (2007) and CEPRI (2008) highlight that networks are rarely considered in flood damage evaluations in France.

Studies analysing the behaviour of networks in hazardous circumstances are useful for understanding network interand intra-connections, such as post-disaster feedback (Lau et al., 1995; Adachi and Ellingwood, 2008), systemic methods for evaluating the vulnerability of network infrastructures to earthquakes (Menoni et al., 2002), and interdependencies between different networks (Rinaldi et al., 2001; Petit et al., 2004; Robert, 2002; Robert et al., 2003a,b,c; Chiaradonna et al., 2011; Ge et al., 2010; Johansson and Hassel, 2010; Ouyang et al., 2009).

The resilience of socio-economic systems to floods is intrinsically linked to the capacity of network owners and operators to deal with flood damage and dysfunctions during and after floods (Pelling, 2003). Understanding the vulnerability of network infrastructures and their functioning and potential for dysfunction in the case of a natural disaster lies at the core of urban resilience to natural hazards. Obtaining knowledge concerning the vulnerability of network infrastructures is also the main step toward the construction of schemes for reducing flood-related risks. However, the complexity of network infrastructures, their technical components and the different links and dependencies between them are some of the primary factors in the current 
misunderstanding of their damage-dysfunction potential in the case of flooding. The complex organization of systems also contributes to the multitude of risks to which network infrastructures are vulnerable (Narbonne, 2005; Petit, 2009). The consequences of floods on these infrastructures depend on the complexity of the overall structure of their components and their material, functional and structural vulnerability (Blancher, 1998; Ecodécision, 2001; CERTU, 2002; MEDD, 2005b; SOGREAH and ASCONIT, 2006; Petit, 2009). The following diagram represents the different relationships between network components and how flood impacts propagate through them (Fig. 1).

When a network component is reached by floodwater, its material vulnerability determines whether or not it may suffer damage. Similarly, its functional vulnerability determines its potential for dysfunction. In Fig. 1, the intradependencies between network components are represented by the structural links between components $\mathrm{A}, \mathrm{B}, \mathrm{C}$ and $\mathrm{E}$, and the network interdependence is represented by the structural link between components $\mathrm{B}$ and $\mathrm{D}$. Considering the dysfunction of component A, the transfer of dysfunctions may follow the pathway indicated in Fig. 1. It is noteworthy that a component mission can also be compromised independently of its direct contact with floodwater (components B in Fig. 1). The impact of infrastructure dysfunctions on the functioning of other components is related to the structural vulnerability of these components, i.e. the domino effect (Gleyze and Reghezza, 2007).

Each component of a network has its own vulnerability to floods and network hazards, greatly increasing the complexity of these analyses. The evaluation of network-related risks is subject to substantial uncertainty (Røstum et al., 2008). The need for network damage and dysfunction evaluation methods has been highlighted by several studies (Bouchon, 2005; Røstum et al., 2008; Petit, 2009; Merz et al., 2010; CEPRI, 2008; D4E, 2007). Despite the fact that understanding this process is crucial to strengthen the resilience of a territory, no standard method exists for forecasting the dysfunctions that can occur in network infrastructures. Supplementary approaches are necessary for taking into account the functional and systemic aspects of networks (Gleyze, 2005; Léone, 2007). A systematic approach that takes into account internal damage to network infrastructures and potential dysfunctions on an elementary scale is therefore needed to analyse their disruption and external damage (Robert, 2002).

\section{Objectives}

The present work aims at making up for the lack of damage and dysfunction assessment methods highlighted in the literature. We propose a new methodology for analysing the internal vulnerability of network infrastructures to floods. In contrast to existing approaches, this method provides an elementary description of networks by developing

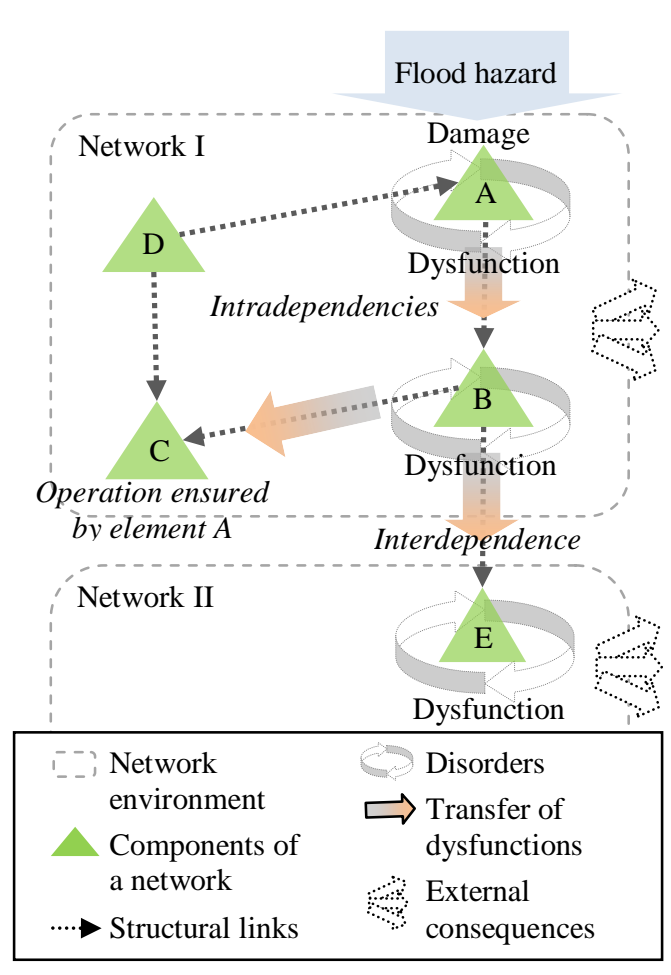

Fig. 1. Relationships between network infrastructures in case of flooding.

damage-dysfunction matrices that place the individual components of the network at the centre of the analysis. We focus on both the damage and dysfunctions generated inside the network environment, possibly leading to the disruption of services. The methodology takes into account the systemic organization of networks, their material and functional vulnerability and their intra- and interdependency. It is based on the following principles: the network is considered as a group of components with specific functions and vulnerabilities; the creation of damage-dysfunction matrices for summarising the information regarding the different components of networks; and the help and involvement of network experts in order to develop the damage-dysfunction matrices. These different principles and the different steps of the method are presented in Sect. 3. We illustrate the method with a case study performed in Alsace, eastern France. Section 4 of this work presents the results of the method, highlighting its advantages, limits and drawbacks.

\section{Method}

The analysis developed here brings together qualitative and quantitative aspects of flood risks in order to summarise the functioning and vulnerability of networks. It determines the damage and dysfunction of the components of a network in the case of floods as well as the types of action required 


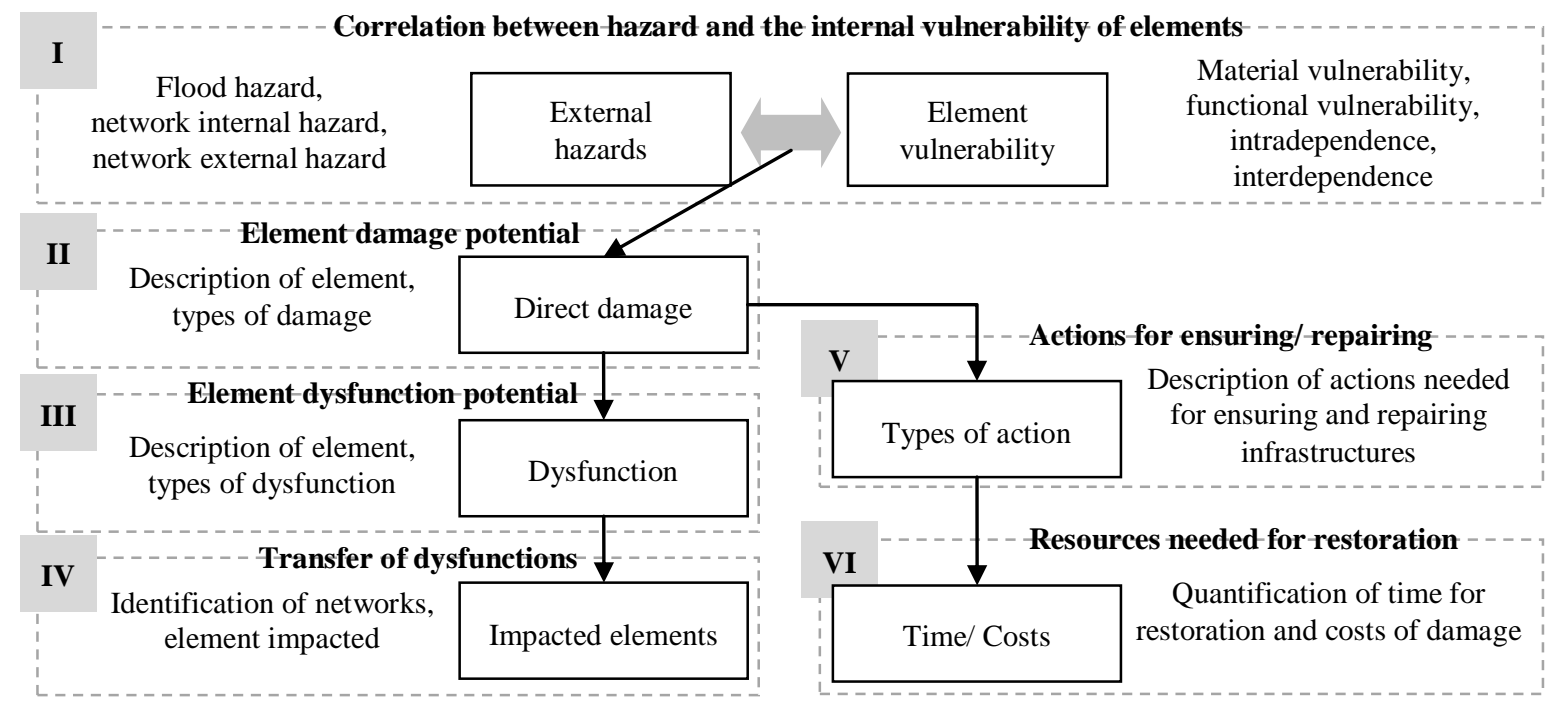

Fig. 2. Structure of damage-dysfunction matrices.

and the resources necessary for dealing with them. A network component damage-dysfunction matrix is organised in 6 charts correlated as shown in Fig. 2.

We consider that each component of the network is vulnerable to external hazards by direct contact with floodwater, i.e. flood hazard, or by the transfer of vulnerability from other components, i.e. network hazard. Chart I (Fig. 2) is the core of the methodology. It provides a quantitative description of the circumstances that may cause damage and/or dysfunctions to the component analysed. The damage and dysfunctions of this component can be the origin of other network hazards, by transferring dysfunctions to other components. Charts II and III provide qualitative descriptions of the potential types of damage and dysfunction to components. They describe the consequences of the hazards to the component analysed. Chart IV identifies which components from the same network can be impacted by the dysfunction of the given component. This impact depends on the potential of the component to transfer vulnerability, which in turn depends on the structural organisation of the network analysed. Chart $\mathrm{V}$ describes the different actions necessary to ensure the operation of the given component or to repair damage. Finally, Chart VI summarises quantitative data concerning time and monetary values necessary to ensure the component functions and to repair the damage incurred. The construction of these damage-dysfunction matrices is organized in the three steps described hereafter.

\subsection{STEP 1: data collection and interview organisation}

The first step of the present method consists of gathering information on the network under analysis in order to: (1) rank its different components according to their functional hierarchy and their damage-dysfunction potential; (2) identify experts and organize interviews.

\subsubsection{Elementary organisation of the network}

Understanding the structural organisation of the network starts with the classification of the different missions within the network. It is also essential to identify the different components necessary for these missions and their technical apparatus. For example, in Table 1 we present the different components and technical apparatus used to perform the different missions of the combined sewerage and drainage network. This stage establishes a synthetic network by listing its different elements and their specific missions. It also promotes an initial level of understanding of the different relationships between the components inside the networks (cf. Fig. 1). Technical studies describing the organisation and the composition of network infrastructures are necessary to summarise their structural operation. They are also necessary to identify which components of the network can be potentially impacted by floods, in order to take the construction of damage-dysfunction matrices further. According to Petit (2009), the functions of a network's components can be classified as "critical" and "support". This classification is established according to the difference of the functional importance of a network's components, for example, the failure of an electricity transformer leads to the dysfunction of several subsequent components of the power network, which is not the case for the dysfunction of an individual electricity connection that would not affect the operation of the system. Penning-Rowsell et al. (2005) and Scawthorn et al. (2006b) proposed classifications based on filtering processes in which only some of the network components are 
Table 1. Description of the combined sewerage and drainage network distinguishing its missions, components and technical apparatus.

\begin{tabular}{|c|c|c|}
\hline Missions & Components & Technical apparatus \\
\hline \multirow[t]{2}{*}{ Collect sanitary and storm flows } & Customer service connection & $\begin{array}{l}\text { Customer sewerage, backwater valve, inspection chamber, } \\
\text { public sewage water pit. }\end{array}$ \\
\hline & Drain system & Curb, gully pot (catchbasin), manhole. \\
\hline \multirow{2}{*}{ Transport wastewater } & Sewerage pipelines & Gravity pipes, pressure pipes, connections. \\
\hline & Pumping station & $\begin{array}{l}\text { Screens, collection tank, pump, power supply box, alarm equip- } \\
\text { ment, ventilation pipe, backwater valve, isolating valve. }\end{array}$ \\
\hline \multirow{2}{*}{ Maintenance of network } & Manhole & Inspection chamber, ventilated manhole, \\
\hline & System cleaning & Flushing tank, outlet mechanism. \\
\hline \multirow{2}{*}{ Retention of fines and suspended solids } & Sludge/mud trap & - \\
\hline & Screening system & Screen, chamber, motor. \\
\hline Discharge of excess wastewater & Combined sewer overflow & Related bypass, wastewater storage tank, control device. \\
\hline \multirow[t]{2}{*}{ Storage and treatment of wastewater } & Sewage treatment plant & $\begin{array}{l}\text { Utility buildings, coarse screens, tanks (sedimentation, aeration, } \\
\text { sludge, etc.), clarifier, sludge digesters, mechanical equipments, } \\
\text { electric equipments, chlorine contact chamber, control rooms. }\end{array}$ \\
\hline & Reservoir, lagoon & - \\
\hline Discharge of treated water into environment & Outfall system & Outfall sewer, backwater valve. \\
\hline
\end{tabular}

selected for in-depth analysis. They focused on the real relationships between network components at risk, for example, the comparison of the number of nodes connected to specific components. Instead, the classification proposed here focuses on the general systemic organisation of networks. We classify its components hierarchically according to their theoretical structural dependencies. This classification allows establishing the functional hierarchy between the different network components.

\subsubsection{Semi-structured interviews}

The involvement of network operators, utilities and technical staff is crucial in order to understand networks (CERTU, 2002). The construction of these damage-dysfunction matrices is mainly based on expert knowledge in order to fully comprehend the links between different components of networks and determine their technical characteristics and vulnerability. As for the construction of damage functions (Green et al., 2011), we suggest that a variety of experts should be consulted. It is indeed necessary to identify the different stakeholders as sources of practical knowledge and to prepare the expert interviews. Individual and grouped semistructured interviews must be prepared in order to fully apprehend the expert technical knowledge obtained. The interviews developed here focus on three main topics:

- direct impacts and cost of damage - to identify which components are the most susceptible to suffer damage in the case of floods and describe the types of damage and induced costs for the different network components;
- vulnerability indicators - to describe the essential vulnerability parameters for the different network components, their material and functional vulnerabilities, their dependence on other network infrastructures, their probability of incurring damage by considering different flood scenarios and potential vulnerability reduction measures;

- indirect impacts and transfer of vulnerability - to list and quantify what is necessary for re-establishing the functions of the different network components, analyse the relationship between direct and indirect internal dysfunctions, and identify the consequences of component dysfunctions on the other network components analysed.

A fourth topic related to the availability of Geographic Information System (GIS) and feedback data is also developed in order to guide the construction of damage-dysfunction matrices for general applications. All these discussions have to be oriented to perform a general analysis of a hypothetical network, in order to avoid and/or identify site-dependent characteristics.

\subsection{STEP 2: damage-dysfunction processes}

This step analyses the way the different components of a network can suffer damage or compromise their specific functions by considering their multiple vulnerabilities, i.e. damage-dysfunction processes. On the one hand, this step consists in determining the material and functional vulnera- 
bilities of different components in direct contact with floodwater. On the other hand, it analyses the components' structural vulnerability correlated with the potential of networks to transfer vulnerabilities due to their systemic organisation. These two aspects are analysed on the basis of expert knowledge and form the core of the method leading to the development of Charts I, II, III and IV of the damage-dysfunction matrices (Fig. 2).

\subsubsection{Material and functional vulnerability}

The evaluation of both material and functional vulnerabilities is necessary in order to comprehend the potential dysfunctions of network infrastructures (Hubert and Ledoux, 1999). Different types of internal damage can occur in a given component, e.g. short-circuiting of electronic devices, destruction of fragile technical apparatus, etc. However, a network's components can be exposed to floodwater and continue to ensure their function, for example, an electronic device within a specific network can be vulnerable to floodwater and suffer damage without ceasing to function, or not suffer damage but nonetheless stop functioning, for instance, a mechanical device can be protected against water by an interruption mechanism, which will stop its operation in the case of a flood. A technical analysis of the different components of the network is necessary at this stage of the methodology in order to distinguish and identify both types of vulnerability of network components. Understanding of the component's susceptibility to floodwater is crucial for the analysis. The approach adopted is based on an ex ante analysis using "what-if" questions to construct stage-damage functions (Merz et al., 2010; Messner et al., 2007). During the semi-structured interviews with experts, several flood scenarios are considered to analyse the different types of components (cf. Fig. 3). This approach makes it possible to establish the correlation between hazard characteristics and component vulnerabilities, with the ultimate goal of determining which circumstances could cause damage and/or dysfunctions to components. This leads to the construction of qualitative damage functions that describe the types of potential material damage to a component $\left(\right.$ Dam $\left._{\text {material }}\right)$ as a function of flood hazard parameters $\left(F_{\mathrm{par}}\right)$, and its material vulnerability ( $\left.V_{\text {mat }}\right)$ (Eq. 1). Furthermore, we describe the types of potential direct dysfunction of a component $\left(\right.$ Dys $_{\text {direct }}$ ) as a function of its potential material damage, its functional vulnerability $\left(V_{\text {func }}\right)$ and crisis organisation aspects (Eq. 2). These functions are integrated in Chart I of the damage-dysfunction matrices (Fig. 2).

$\operatorname{Dam}_{\text {material }}=f\left(F_{\text {par }}, V_{\text {mat }}\right)$,
Dys $_{\text {direct }}=f\left(\right.$ Dammaterial $\left._{\text {manc }}, C_{\text {org }}\right)$.

In order to illustrate this stage, we describe the vulnerability analysis concerning the pressure regulator station of a gas distribution network. We represent this specific component

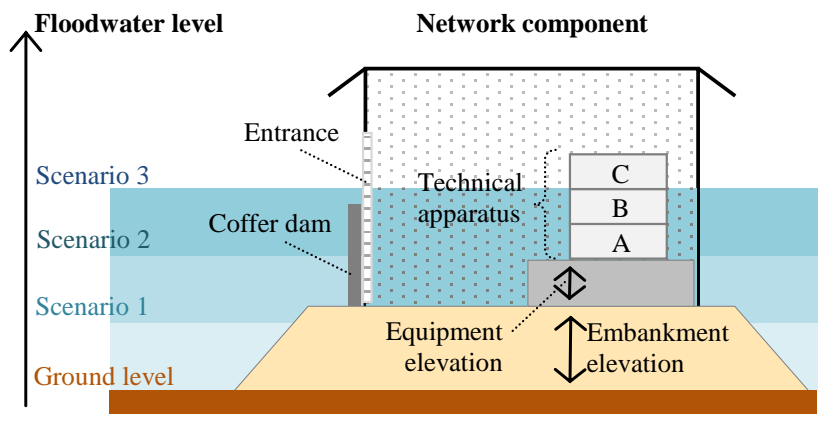

Fig. 3. Flood vulnerability indicators for consideration in the analysis of network component susceptibility to damage and dysfunctions due to direct contact with floodwater.

in Fig. 3 considering that: the technical apparatus " $\mathrm{A}$ " corresponds to the utility box and the technical apparatus " $\mathrm{B}$ " corresponds to the distance-monitoring device. Contact between the item of equipment with floodwater depends on the water level, the elevation of the infrastructure supporting the component, the arrangement of the technical apparatus inside the component and, finally, the existence of flood protection devices (e.g. coffer dam). Only flood scenario "3" implies the contact of floodwater with the technical apparatus (Fig. 3). In this case, the contact of floodwater with apparatus " $\mathrm{A}$ " can induce the failure of the equipment due to overpressure or the mechanical failure of the device, depending on the type of equipment. The contact of floodwater with apparatus "B" may lead to the short-circuiting of the equipment. These types of direct damage must be described in Chart II (Fig. 2) of the corresponding damage-dysfunction matrix (cf. Fig. 4). The failure of apparatus "A" may lead to different dysfunctions of the network component, which may compromise its mission within the network, e.g. disruption of distribution, reduction of delivery pressure or increase of delivery pressure. These types of dysfunctions must be described in Chart III (Fig. 2) of the corresponding damagedysfunction matrix (cf. Fig. 4).

Regarding the hydraulic hazard parameters, i.e. water depth, flow velocity, duration of submersion, sediment and debris transport, they play different roles regarding damage potential, depending on the type of asset analysed (Thieken et al., 2005; Léone, 2007; Messner et al., 2007; Merz et al., 2010). Each component of the network has to be analysed separately, taking into account detailed technical characteristics in order to identify their main damage impact parameters. The correlation of damage and dysfunction with water depth is preferable for practical applications. The influence of other parameters should be analysed so as to further refine this analysis. 


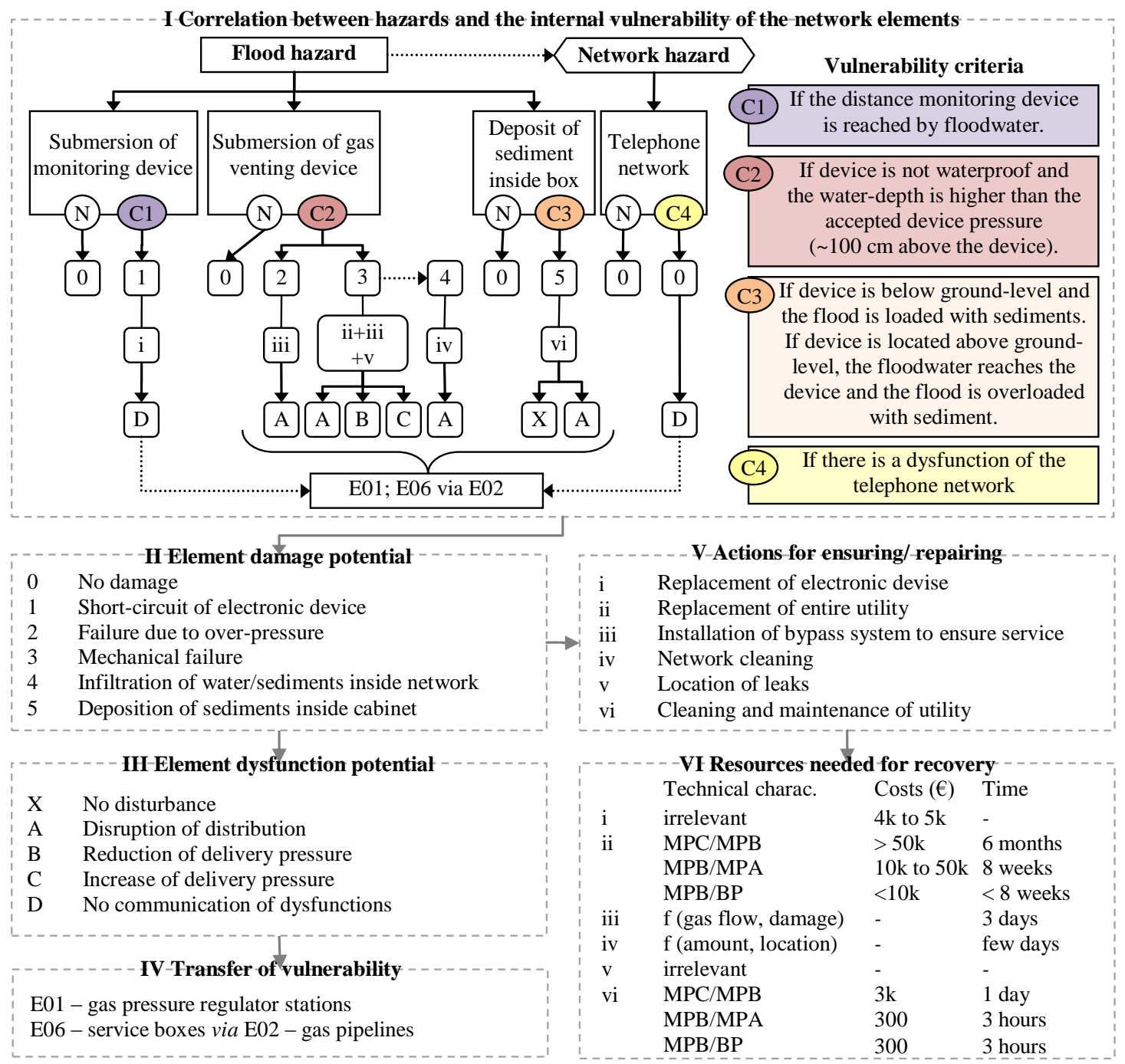

Fig. 4. Damage-dysfunction matrix - pressure regulator station of the gas distribution network.

\subsubsection{Structural vulnerability}

We describe the types of potential structural dysfunctions of a component qualitatively as a function of two variables: the component's degree of intradependence and its degree of interdependence. The degree of intradependence between two components is measured by evaluating the potential of the network component to transfer dysfunctions to other components hierarchically equal to or below it. For example, the dysfunction of a control/power supply box in the public lighting network may lead to the dysfunction of all the street lighting columns connected to this item of equipment. Another example concerns the dysfunction of the gas network pressure regulator station that may lead to the dysfunction of other gas pressure regulator stations as well as the service boxes connected to it. Interdependence is correlated to the dependence of a component on services supported by other networks (Røstum et al., 2008), e.g. exchanges between components $\mathrm{B}$ and $\mathrm{E}$ (Fig. 1). The same analysis is performed to take into account this parameter in the evaluation process. We measure the degree of interdependence of a component by investigating the dependence of its technical apparatus on components from other networks. Considering the example of the gas network pressure regulator stations, the distance monitoring device now represented by apparatus " $\mathrm{C}$ " (Fig. 3) may dysfunction if the telephone network fails, even though it is not reached by floodwater. This information must be represented in Charts I and IV (Fig. 2) of the damagedysfunction matrix (cf. Fig. 4).

\subsection{STEP 3: quantification of damage and dysfunctions}

This step quantifies damage to networks by considering the different actions and resources needed to deal with them. We 
describe the types of action and quantify the costs and time necessary to ensure or restore the operation of a network component. It is used to develop the damage-dysfunction matrices, thus completing Charts V and VI (Fig. 2). It is also based on expert information and can be carried out in parallel to the second step. However, the quantitative aspect explored here is linked to the context in which the analysis is performed, i.e. it is site-dependent.

\subsubsection{Measures for ensuring functions/repairing infrastructures}

Network utilities and operators have to deal with the dysfunctions of a component in order to avoid damage to, and disruptions of, the services offered by their network. In this stage, we describe the actions that must be carried out during a flood event (generally to avoid material damage and/or ensure the continuity of the services offered by the network), or after a flood event (to repair damage, check the components and restore the operation of disrupted services). These actions are correlated with the different types of damage identified in the previous steps. For example, if floodwater reaches a power transformer station, the previous step allows concluding that it may be damaged by a short-circuit, leading to the dysfunction of the service boxes connected to this station (due to the absence of power). At this stage of the analysis we conclude that: (1) during the flood event, the dysfunction of other network components may be avoided by insulating the damaged component (installation of a bypass system to ensure that the service continues); (2) after the flood event, the equipment may be cleaned and possibly repaired or replaced, depending on the degree of damage incurred. Organizational aspects of the network operators and utilities are understood on the basis of expert interviews at this stage. This information must be represented in Chart V (Fig. 2) of the damagedysfunction matrix (cf. Fig. 4).

\subsubsection{Resources necessary for adopting measures}

Methods used for assessing earthquake damage also take this aspect into account (Scawthorn et al., 2006a, b), as it is essential in order to proceed from the "evaluation stage" to the "action stage". On the one hand, we identify the amount of time necessary for adopting a specific measure, e.g. time necessary for replacing a water pump, or the time necessary for cleaning a gas distribution network component. On the other hand, we quantify the costs necessary in order to repair, replace and/or clean affected elements. This data must be represented in Chart VI (Fig. 2) of the damagedysfunction matrix (cf. Fig. 4). Several studies propose quantifying the damage potential of an asset as a percentage of its initial value (Léone, 2007; Messner et al., 2007; Jonkman et al., 2008; Penning-Rowsell et al., 2005). In the case of network infrastructures, we also note that the replacement costs necessarily incorporate the expenses generated by the short period within which the continuity of services must be ensured. This can offset the real damage, which can be more significant than material losses, thereby justifying the correlation of the resources with the different potential measures for ensuring the functions of the element or repairing infrastructures.

\subsection{Case study}

To apply the methodology proposed in this paper, several national studies were used in order to understand and gather the information related to the different networks analysed (step 1 of the method). Technical information on networks can be found in professional documentation (RTE, 2004; SETRA, 1996a,b; Hamou, 2005; Vazquez et al., 2006) and on the websites of the network's stakeholders ${ }^{2}$. The following lifelines and infrastructures were analysed: sewerage and drainage, water supply, public lighting, gas distribution and power supply networks. Sixty experts from different institutions associated with networks were interviewed ${ }^{3}$ to construct the damage-dysfunction matrices (steps 2 and 3). With them, we analysed the structure of the different networks, by redefining the specific functions of the different components and the links between them. Twenty-five components belonging to the different networks were selected for in-depth analysis (Table 2).

The damage-dysfunction matrices were used to analyse the potential impacts of flooding of the Bruche river on six towns in eastern France: Holtzheim, Oberschaeffolsheim, Wolfisheim, Eckbolsheim, Lingolsheim and Strasbourg. GIS data relating to a theoretical flood event with a 100-yr flood return-period were used to evaluate potential damage and dysfunctions to network infrastructures. The application of the damage-dysfunction matrices implies collecting data related to the network infrastructures analysed, and following the application of a classical flood damage evaluation method (Merz et al., 2010). Exposure analyses were performed to locate the network components within the area studied (GIS data sets of local networks were used during these analyses). Susceptibility analyses were performed to identify component vulnerability criteria and technical characteristics (cf. Fig. 3) in cooperation with local network managers. Finally, a GIS-based method (Eleutério et al., 2010) was used to automatically combine the different data and calculate the damage and dysfunction potentials of the different components analysed.

\footnotetext{
2 DirectIndustrie, Schneider-Electric, VHM-Heinrich, laviedesreseaux.fr, BVP, RTE, EDF, GRT-Gaz, GDF-SUEZ, Afgaz, Astee.

${ }^{3}$ The list of the experts and their institutions may be requested from the authors.
} 
Table 2. The network components analysed for the construction of damage-dysfunction matrices.

\begin{tabular}{ll}
\hline Network & Components \\
\hline Water supply & Water borehole, water treatment plant, pumping station, water pipelines. \\
Sewerage and drainage & $\begin{array}{l}\text { Station, sludge/mud trap, combined sewer overflow, automatic screening, outfall sewer, drain } \\
\text { system, lagoon, sewage treatment plant, sewage pipelines. }\end{array}$ \\
Power supply & $\begin{array}{l}\text { Electrical substation (high voltage), power transformer station (high voltage/low voltage), pole } \\
\text { and distribution line (high voltage), service box. }\end{array}$ \\
Gas distribution & $\begin{array}{l}\text { Pressure regulator station, switching substation, cathodic protection box, service box, shut-off } \\
\text { valve, gas pipe. }\end{array}$ \\
Public lighting & Control and power-supply box, street lighting columns, floor luminary. \\
\hline
\end{tabular}

\section{Results}

\subsection{Damage-dysfunction matrices}

Damage-dysfunction matrices were developed for the different components analysed ${ }^{4}$. As an example, we present in Fig. 4 a simplification of the damage-dysfunction matrix developed for analysing the pressure regulator station of the gas distribution network.

This damage-dysfunction matrix summarises how damage and dysfunctions can occur to the component in question when it is reached by floodwater or impacted by the dysfunction of components of other networks (in this case, access to the telephone network). Chart I (Fig. 4) of this damagedysfunction matrix provides a schematic view of the qualitative damage functions of the component analysed (Eqs. 1,2) and its different dependencies on other components. The interviews revealed that, quantitatively, the network experts are unable to take into account parameters other than water depth, although they insisted that other parameters could also play an important role in damaging components. The resources for restoring the services provided by networks, following floods, take into account the costs of replacing the damaged material (technical apparatus and labour costs) and the estimated time required to do it (Chart VI, Fig. 4). These resources depend on the technical characteristics of the component and the context of the study.

\subsection{Evaluation of damage and dysfunctions}

The key result of this method is the determination of the types of potential damage and dysfunctions generated by the floods in the networks analysed. Figures 5 and 6 show the internal dysfunction maps of the network obtained by applying the matrices developed in this work.

In Fig. 5 we analyse two interdependent networks in a flood context: the power supply and public lighting networks. The different relationship between the components of these

\footnotetext{
4 The set of damage-dysfunction matrices used to illustrate this case study can be found in Hattemer (2010).
}

networks (cf. Fig. 1) are demonstrated, taking a power transformer station (component A in Fig. 5) as an example. This component is potentially damaged by the submersion of its technical apparatus: a short circuit revealed by the technical analysis of the relationship between the flood hazard and the component vulnerability indicators (cf. description of example in Fig. 3). This damage generates a primary dysfunction of the component, i.e. the disruption of power supply to related connections. The dysfunction of this component generates other subsequent dysfunctions due to the structural vulnerability of the network:

- dysfunction of components of the same hierarchic level - other transformers directly connected (connection in series) to it, e.g. a transformer not reached by floodwater (component B in Fig. 5). The experts suggested that the components located within a distance less than $300 \mathrm{~m}$ from the damaged transformer have a high probability of being affected by the dysfunction. In an urban context, the longer the distance from the dysfunctional transformer is, the greater the uncertainty, once there is a possibility of the component being linked to another transformer in parallel. Network node analyses can be used to reduce this uncertainty. The second level of dysfunction is not represented on the map due to the high level of uncertainties, for instance, crisis management can be structured in order to avoid this second level of dysfunction by isolating the dysfunctioning transformers and by using different sources of power supply for the others.

- dysfunction of service boxes due to the absence of energy. The transfer of vulnerability to hierarchically low components (service boxes) connected to the failed component, e.g. service box not reached by floodwater (component $\mathrm{C}$ in Fig. 5). The dysfunction of service boxes leads to other dysfunctions, such as other service boxes connected in series, and external damage, for example, damage to the clients connected to the service boxes. 


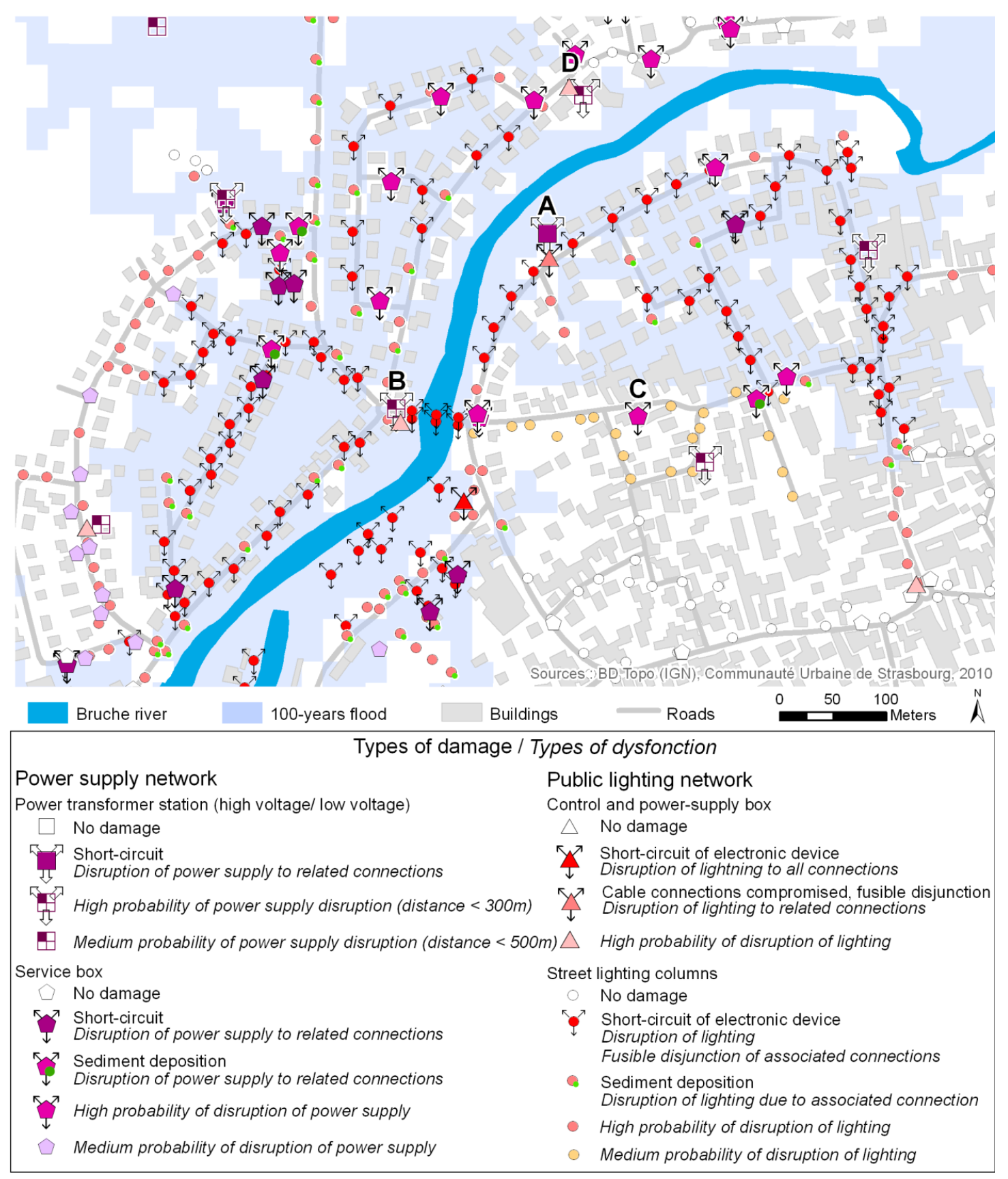

Fig. 5. Map of damage-dysfunctions caused by a flood with a 100-year return-period for the components of public lighting and power supply networks.

The analysis of public lighting network dysfunctions is similar to the previous one. The contact of floodwater with network components can generate damage and/or dysfunctions. These dysfunctions can be transferred to other components within the network owing to their intradependence, e.g. the transfer of dysfunctions from control/power supply boxes to street lighting columns in Fig. 5. One difference with the previous example is that the operation of the public lighting network depends on the power supply network, i.e. network interdependence. The dysfunction of a power transformer station may cause the dysfunction of public lighting network components. For example, the public lighting control and power supply box (component D in Fig. 5) may suffer from power failure due to the disruption of the power transformer station (component B in Fig. 5). This disruption generates secondary indirect dysfunctions to street lighting columns 


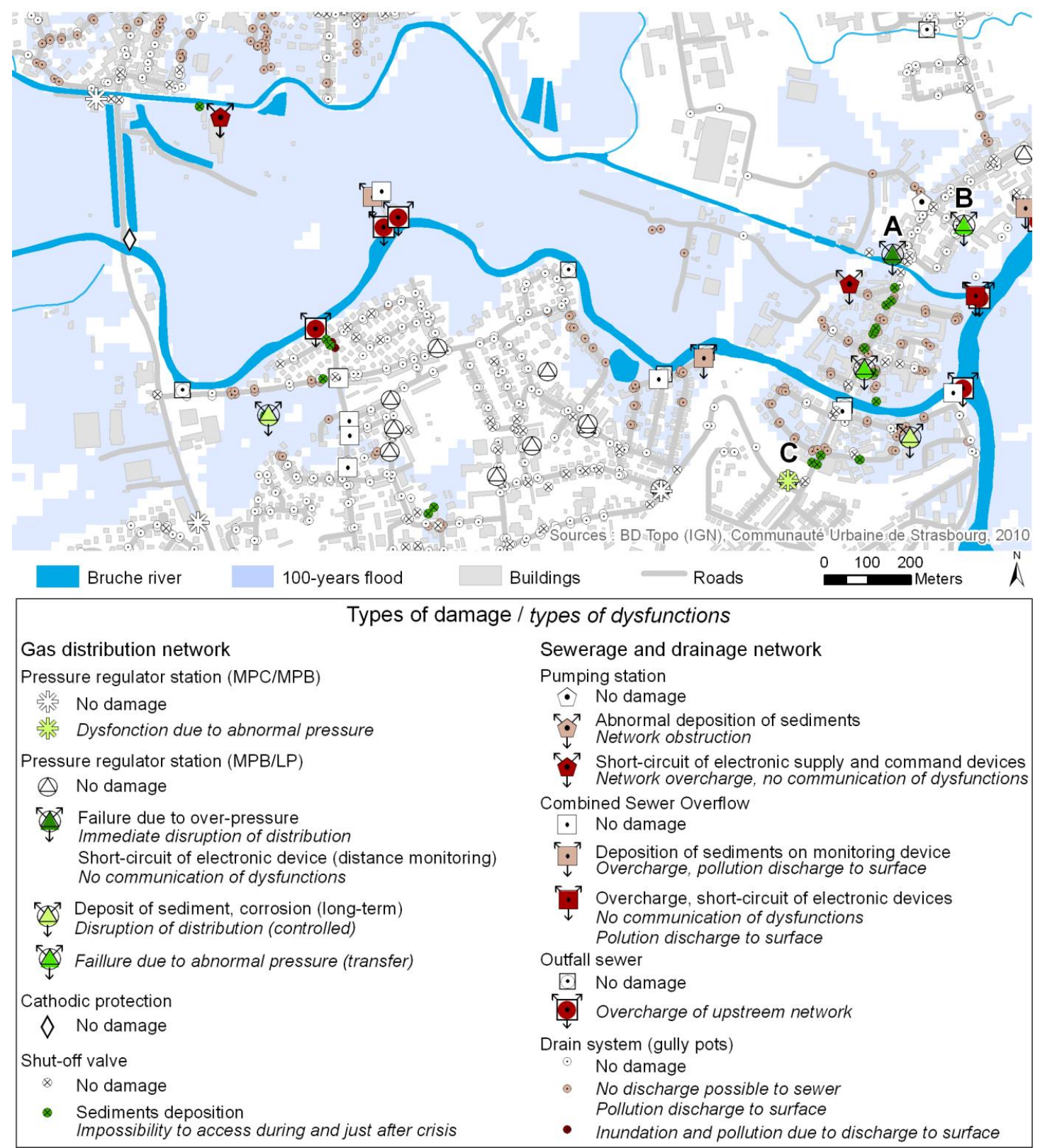

Fig. 6. Map of damage-dysfunctions caused by a 100-year return-period flood for the components of gas distribution and sewerage/drainage networks.

connected to this element. Modelling approaches based on the structural links of the network can be used to enhance the analysis of the transfer of vulnerability between components.

Figure 6 analyses the potential damage and dysfunctions of gas distribution and sewerage/drainage networks. As an example, we analyse the dysfunction of the pressure regulator station $\mathrm{MPB} / \mathrm{LP}$ due to the submersion of its gas venting device and monitoring device (component A in Fig. 6). The damage-dysfunction matrix of this component (Fig. 4) illustrates its vulnerability to floods and its relationships with other network components. The damage caused to these apparatuses causes the immediate disruption of gas distribution. As with the previous example, this dysfunction is propagated to other components outside the flooded area, such as to other pressure regulator stations MPB/LP connected to it (components B and C in Fig. 6) and to customers' service boxes also connected to it (not represented in the map). The components affected by this deregulated pressure may stop operating automatically and be subject to the interruption of gas distribution. However, damage to the distance monitoring device 


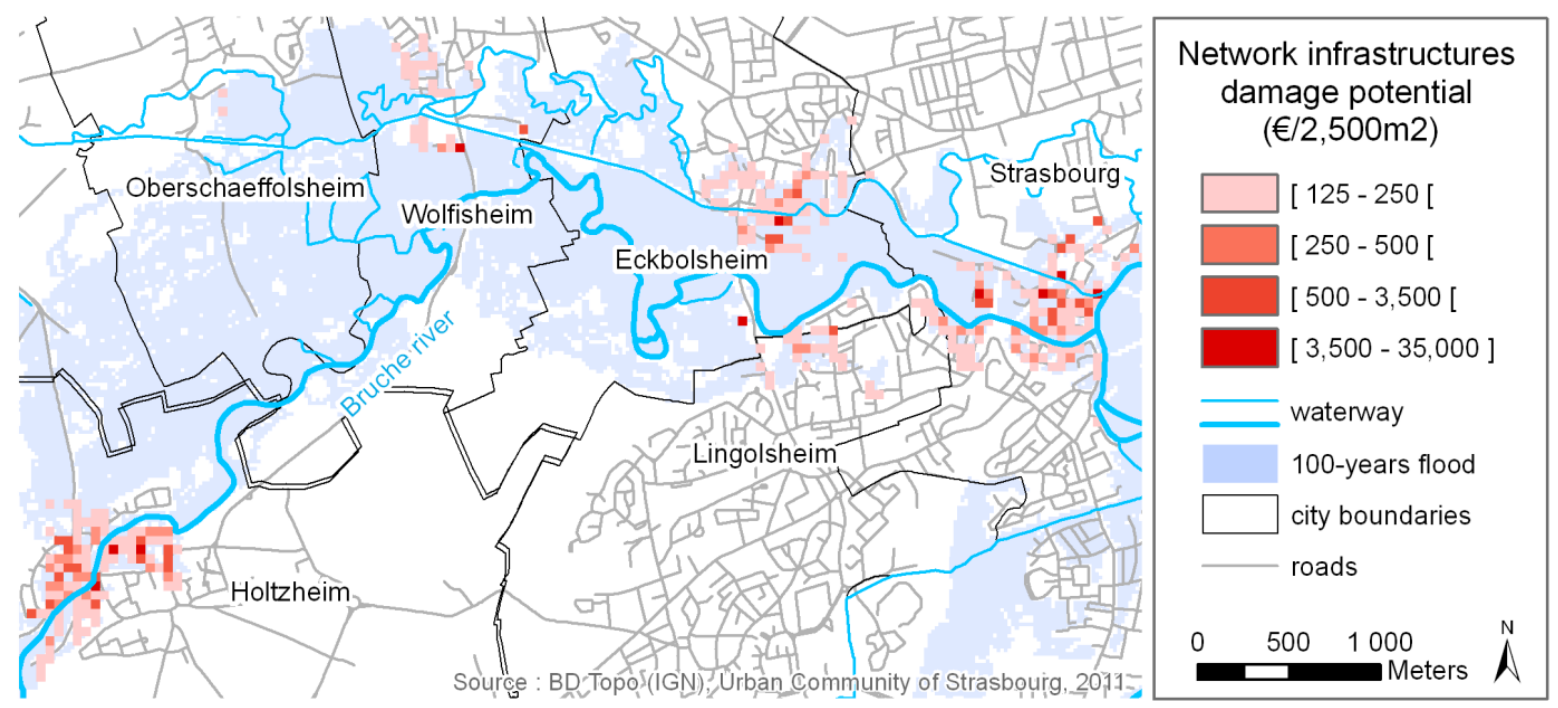

Fig. 7. Map of damage costs caused by a 100-yr return-period flood on the grouping of the network components analysed: sewerage and drainage, public lighting, gas distribution and power supply.

(inside the pressure regulator station) may lead to the noncommunication of the pressure regulator station dysfunction to the network managers. This type of dysfunction will reduce the possibility of the managers to act during the crisis period, increasing the risk of propagation of dysfunctions inside and outside the network.

These maps can be used for anticipating potential network dysfunctions, thus fostering crisis management policies. The information contained in this case study promotes reflexion on what kind of measure should be adopted in order to reduce the flood risk and ensure network continuity. For example, it reveals that in case of flooding, a damaged component (component A in Fig. 6) should be insulated by the installation of a bypass system to ensure the service to equipment downstream. It also reveals that the dysfunction of this component would not necessarily be known during the crisis period. The interdependence of this component with the telephone network can also lead to the non-communication of dysfunctions, if any. This information allows the crisis manager to anticipate and re-think crisis management policies. The identification of the location of shut-off valves, which could not be accessed during or just after a crisis (cf. Fig. 6), also fuels crisis organisation planning, as it must be possible to gain access to them to avoid the propagation of dysfunctions.

The results of this evaluation are shown on a general damage map (Fig. 7). This map represents the potential direct internal damage of a 100-yr flood to the network infrastructure analysed. It consists of the sum of the potential damage (replacement/repair costs) for the different components of the overall networks analysed. This damage is located exclusively inside the flood area and represents only part of the total damage caused by floods on the network infrastructure.
This estimation of potential monetary damage is useful for aiding flood management projects (Messner et al., 2007; Merz et al., 2010). It allows determining areas that concentrate potential direct damage, thereby helping in the design of flood protection projects and policies.

\subsection{Discussion}

The results presented here describe the potential of the method to apprehend the complexity of networks in case of floods. Maps identifying the different components of a network and their damage-dysfunction potentials are powerful tools for aiding actions to reduce vulnerability and for estimating the external consequences of hazard networks, i.e. indirect damage. The elementary comprehension of the network should considerably aid ex ante policies for protecting networks from risks. However, the present case study reveals the difficulty of correlating flood parameters with the vulnerability of network components, due to the lack of technical knowledge of how the different components of the network react to different flood parameters. Nevertheless, the experts emphasised that the duration of submersion, flow velocity and the amount of sediment/debris carried by floodwater are crucial parameters influencing damage and dysfunction. This is in line with the findings of Kreibich et al. (2009), who identified that transport infrastructures may be strongly influenced by flow velocity and the need for this parameter to be taken into account by structural damage forecasting. They also revealed the difficulty in apprehending the intra- and interdependences of different network components. However, they highlighted the essential roles of the power-supply and transport networks in the interdependence of networks 
during flood events. Several crisis management actions depend on access to specific premises and the availability of power.

A disadvantage of this method is the amount of data needed for the application of damage-dysfunction matrices. The collection of data relating to the different network infrastructures proved to be the most difficult step during the application of our damage-dysfunction matrices. It was stated that few data on network infrastructures are available, as highlighted by Merz et al. (2010), and when data are available they may not be accessible due to safety or strategic reasons. Furthermore, when data is accessible, it rarely corresponds to the level of detail required for analyses. We also observed that network managers and operators do not completely comprehend the systemic complexity of their networks, as inferred by the lack of data and models within their organisations. The application of graph theory for analysing complex network organization is one of the approaches that could be used for estimating such complexity (Gleyze, 2005; Jenelius et al., 2006; Sohn, 2006; Winkler et al., 2010). We suggest conducting the evaluation by taking a long-term view within the organisations and companies responsible for managing networks in order to conserve the intrinsic systemic nature of the potential risks. This would lead to better understanding of the systemic complexity of the networks involved.

This method is still marked by a considerable degree of uncertainty, notably regarding the estimation of resources necessary for repairing/restoring components. This involves values that depend on several criteria, such as the importance of the component for the operation of the network, the possibility of temporarily bypassing the component, the existence of the component on the local market, the specific characteristics of the component if civil engineering works are necessary, labour costs, etc. This uncertainty must be considered when using these matrices. This high-level of uncertainty could be explained by the lack of feedback on previous damage and the number of factors governing damage to infrastructures (Dutta et al., 2003). Field surveys and the involvement of the constructors responsible for building the technical equipment of networks could help to reduce these uncertainties.

\section{Conclusions and perspectives}

The evaluation of damage and dysfunctions inside the network environment and of the structural vulnerability of network infrastructures, proved essential for understanding their susceptibility to floods. The general methodology presented here aimed at making up for the lack of damage and dysfunction evaluation methods highlighted in the literature (Bouchon, 2005; Røstum et al., 2008; Petit, 2009; Merz et al., 2010; CEPRI, 2008; D4E, 2007). The significant involvement of network experts in our method leads to better understanding of the organisation of networks and their vulnerabilities. When considering networks at an elementary scale, we were able to identify the most relevant infrastructures in terms of potential damage and dysfunctions, thus providing operators with the knowledge necessary to improve the resilience of their networks. This approach encourages analyses of interdependencies between networks and, consequently, multi-network analyses (Petit, 2009; Dudenhoeffer et al., 2006; Røstum et al., 2008). Further research should focus on the comprehensive description of interdependences between networks at an elementary scale. The elementary description of assets implies considerable efforts for data collection. However, it limits uncertainties concerning the functioning of a network. The elementary asset-centred description of networks allows the easy transposition of the method developed here to other hazards.

The application of this method in the French context revealed that network managers and operators are extremely interested in this kind of information. The large number of experts and their significant involvement during the different interview sequences reflected this fact. Network stakeholders were curious about our method and expressed their interest in both vulnerability to floods and in reducing infrastructure damage/dysfunctions. The application of the method also revealed that a high level of detailed data is required to understand networks, thus encouraging managers and operators to enhance their organization. The level of uncertainty in the evaluation is wholly dependent on the amount of data, its quality and the experience of local operators regarding flood events. The improvement of knowledge on networks through the increasing use of GIS platforms within network organisations and the attention given to the vulnerability of networks to floods should encourage practitioners to apply systemic methods more frequently, in order to understand the potential operation and dysfunctions of network infrastructures.

Acknowledgements. The authors would like to thank the MAIF Foundation for its financial support and all the experts who participated in this work.

Edited by: D. Serre

Reviewed by: two anonymous referees

\section{References}

Adachi, T. and Ellingwood, B. R.: Serviceability of earthquakedamaged water systems: Effects of electrical power availability and power backup systems on system vulnerability, Reliability Eng. Syst. Safety, 93, 78-88, doi:10.1016/j.ress.2006.10.014, 2008.

Adam, R.: Economic resilience to natural and man-made disasters: Multidisciplinary origins and contextual dimensions, Environ. Hazards, 7, 383-398, 2007.

Blancher, P.: Risques, villes et réseaux techniques urbains, in: Risques et réseaux techniques urbains, edited by: Blancher, P., Collection du certu, CERTU, 13-24, 1998. 
Bouchon, S.: L'application du concept de vulnerabilite aux infrastructures critiques : Implications pour la gestion des risques, Conférence-débat:risques et vulnérabilité, Paris, (21 octobre 2005), 2005.

Bouchon, S.: L'analyse de vulnérabilité pour identifier les infrastructures critiques européennes: Exemple du système gazier en europe, in: Risques et environnement: Recherches interdisciplinaires sur la vulnérabilité des sociétés, edited by: Becerra, S., and Peltier, A., Sociologies et environnement, L'Harmattan, Paris, 215-229, 2009.

CEPRI: Evaluation de la pertinence des mesures de gestion du risque d'inondation: Manuel des pratiques existantes, 2008.

CERTU: Vulnérabilité des réseaux urbains et gestion de crise, Exemple de l'inondation de mars 2001 à lyon et mâcon, Ministère de l'Ecologie et du Développement Durable, Direction de la Prévention des Pollutions et des Risques, Paris, 78 pp., 2002.

Chiaradonna, S., Giandomenico, F. D., and Lollini, P.: Definition, implementation and application of a model-based framework for analyzing interdependencies in electric power systems, Int. J. Crit. Infrastruct. Protection, 4, 24-40, 2011.

Crowther, K. G., Haimes, Y. Y., and Taub, G.: Systemic valuation of strategic preparedness through application of the inoperability input-output model with lessons learned from hurricane katrina, Risk Anal., 27, 1345-1364, doi:10.1111/j.15396924.2007.00965.x, 2007.

D4E: Évaluations socio-économiques des instruments de prévention des inondations, Paris, 117 pp., 2007.

Dawson, R., Peppe, R., and Wang, M.: An agent-based model for risk-based flood incident management, Nat. Hazards, 59, 167189, doi:10.1007/s11069-011-9745-4, 2011.

Demoraes, F.: De l'intérêt d'une étude sur la vulnérabilité des réseaux routiers et de transport pour la compréhension des vulnérabilités territoriales, Le cas du district métropolitain de quito (équateur), Cybergeo: European Journal of Geography, Dossiers. Vulnérabilités urbaines au sud, document 446, 18 pp., doi:10.4000/cybergeo.22101, 2009.

Demoraes, F. and D'Ercole, R.: Risques et accessibilité des lieux dans le district métropolitain de quito (équateur), M@ppemonde, 95, 20 pp., 2009.

Desgranges, P.: L'analyse des désordres et des dommages aux réseaux, in: Le coût du risque...L'évaluation des impacts socioéconomiques des inondations, edited by: Hubert, G. and Ledoux, B., Presses de l'école national des Ponts et Chaussées, Paris, 149-151, 1999.

Dudenhoeffer, D. D., Permann, M. R., and Manic, M.: Cims: A framework for infrastructure interdependency modeling and analysis, Proceedings of the 38th conference on Winter simulation, Monterey, California, 478-485, 2006.

Dutta, D., Herath, S., and Musiake, K.: Direct flood damage modeling towards urban flood risk management, Joint Workshop on Urban Safety Engineering 2001, AIT, Bangkok, Thailand, 127143, 2001.

Dutta, D., Herath, S., and Musiake, K.: A mathematical model for flood loss estimation, J. Hydrol., 277, 24-49, 2003.

Ecodécision: Diagnostic de la vulnérabilité aux inondations des services d'eau, Guide méthodologique, Equipe Pluridisciplinaire Plan Loire Grandeur Nature, Orléans, 44 pp., 2001.

Ecodécision: Evaluation économique des dommages liés aux inondations, rapport final, AEAP (Agence de l'Eau Artois-Picardie),
80 pp., 2006.

Eleutério, J., Martinez, D., and Rozan, A.: Developing a gis tool to assess potential damage of future floods, Risk Analysis VII, Algarve, Portugal, 2010,

Ge, Y., Xing, X., and Cheng, Q.: Simulation and analysis of infrastructure interdependencies using a petri net simulator in a geographical information system, Int. J. Appl. Earth Observation Geoinf., 12, 419-430, 2010.

Gleyze, J.-F.: La vulnérabilité structurelle des réseaux de transport dans un contexte de risque, Thèse de Doctorat, Géographie, Histoire, Sciences de la Société, Université Paris 7 - Denis Diderot, Paris, 539 pp., 2005.

Gleyze, J.-F. and Reghezza, M.: La vulnérabilité structurelle comme outil de compréhension des mécanismes d'endommagement, Géocarrefour, 82, 17-26, 2007.

Green, C., Viavattene, C., and Thompson, P.: Guidance for assessing flood losses, Conhaz report.204344, 80 pp., 2011.

Hallegatte, S.: An adaptive regional input-output model and its application to the assessment of the economic cost of katrina, Risk Anal., 28, 779-799, doi:10.1111/j.1539-6924.2008.01046.x, 2008.

Hamou, B.: Réseaux de distribution d'eau potable, edited by: bâtiment, C. d. p. d., Ginger Cated, 2005.

Hardy, S.: La vulnérabilité de l'approvisionnement en eau dans l'agglomération pacénienne: Le cas du sous-système el alto, Cybergeo : European Journal of Geography, Dossiers, Vulnérabilités urbaines au sud, document 457, $23 \mathrm{pp}$. doi:10.4000/cybergeo.22270, 2009.

Hattemer, C.: Méthodologie d'évaluation de l'endommagement primaire des réseaux d'infrastructures face au risque inondation, Master of science thesis, Montpellier III, Université Paul Valéry Montpellier, 142 pp., 2010.

Henriet, F., Hallegatte, S., and Tabourier, L.: Firm-network characteristics and economic robustness toâ natural disasters, J. Economic Dynam. Control, 36, 150-167, 2012.

Hubert, G. and Ledoux, B.: Le coût du risque, L'évaluation des impacts socio-économiques des inondations, Presses de l'Ecole Nationale des Ponts et Chaussées, Paris, 232 pp., 1999.

Huet, P. D.: Retour d'expérience des crues de septembre 2002 dans les départements du gard, de l'hérault, du vaucluse, des bouchesdu-rhône, de l'ardèche et de la drôme, Rapport consolidé après phase contradictoire, Rapport au ministre de l'écologie et du développement durable, 133 pp., 2003.

Jenelius, E., Petersen, T., and Mattsson, L.-G.: Importance and exposure in road network vulnerability analysis, Transp. Res. Part A: Policy Practice, 40, 537-560, doi:10.1016/j.tra.2005.11.003, 2006.

Johansson, J. and Hassel, H.: An approach for modelling interdependent infrastructures in the context of vulnerability analysis, Reliab. Eng. Syst. Safety, 95, 1335-1344, 2010.

Jonkman, S. N.: Global perspectives on loss of human life caused by floods, Nat. Hazards, 34, 151-175, 2005.

Jonkman, S. N., Bockarjova, M., Kok, M., and Bernardini, P.: Integrated hydrodynamic and economic modelling of flood damage in the netherlands, Ecol. Econom., 66, 77-90, 2008.

Kreibich, H., Piroth, K., Seifert, I., Maiwald, H., Kunert, U., Schwarz, J., Merz, B., and Thieken, A. H.: Is flow velocity a significant parameter in flood damage modelling?, Nat. Hazards Earth Syst. Sci., 9, 1679-1692, doi:10.5194/nhess-9-1679-2009, 
2009.

Lau, D. L., Lau, A., and Pierre, J.-R.: Performance of lifelines during the 1994 northridge earthquake, Can. J. Civ. Eng., 22, 438451,1995

Lefrou, C. D.: Rapport sur les crues des 12, 13, 14 novembre 1999 dans les départements de l'aude, de l'hérault, des pyrénéesorientales et du tarn, Conseil Général des Ponts et Chaussées, Inspection générale de l'environnement, 99 pp. + annexes, 2000.

Léone, F.: Caractérisation des vulnérabilités aux catastrophes "naturelles ": Contribution à une évaluation géographique multirisque (mouvements de terrain, séismes, tsunamis, éruptions volcaniques, cyclones), Mémoire d'Habilitation à Diriger des Recherches (HDR), Géographie, Université Paul Valéry - Montpellier III, Laboratoire GESTER, Montpellier, 245 pp. + Annexes pp., 2007.

MEDD: Fiche de cas: La crue de la meuse et de ses affluents en janvier 1995 dans les ardennes, Ministère de l'Ecologie et du Développement Durable, Direction de la Prévention des Pollutions et des Risques, Paris, 79-99, 2005a.

MEDD: Réduire la vulnérabilité des réseaux urbains aux inondations, Ministère de l'Ecologie et du Développement Durable, Direction de la Prévention des Pollutions et des Risques, Paris, 112 pp., 2005b.

Menoni, S., Pergalani, F., Boni, M. P., and Petrini, V.: Lifelines earthquake vulnerability assessment: A systemic approach, Soil Dynam. Earthq. Eng., 22, 1199-1208, doi:10.1016/s02677261(02)00148-3, 2002.

Merz, B., Kreibich, H., Schwarze, R., and Thieken, A.: Review article "Assessment of economic flood damage", Nat. Hazards Earth Syst. Sci., 10, 1697-1724, doi:10.5194/nhess-10-16972010, 2010.

Messner, F., Penning-Rowsell, E., Green, C., Meyer, V., Tunstall, S., and van der Veen, A.: Evaluating flood damages: Guidance and recommendations on principles and methods, FLOODsite Consortium, Wallingford, 179 pp., 2007.

Narbonne, Y.: Complexité et systémique, edited by: publication, $\mathrm{H}$. S., Lavoisier, Paris, 2005.

Ouyang, M., Hong, L., Mao, Z.-J., Yu, M.-H., and Qi, F.: A methodological approach to analyze vulnerability of interdependent infrastructures, Simulation Model. Practice Theory, 17, 817-828, 2009

Parker, D. J., Green, C. H., and Thompson, P. M.: Urban flood protection benefits: A project appraisal guide (red manual), Gower Technical Press, Aldershot, 284 pp., 1987.

Pelling, M.: The vulnerability of cities, Natural disaster and social resilience, Earthscan Publications Ltd., London, 2003.

Penning-Rowsell, E., Johnson, C., Tunstall, S., Tapsell, S., Morris, J., and Chatterton, J.: The benefits of flood and coastal risk management - a manual of assessment techniques, edited by: (FHRC), F. H. R. C., Defra, London, 2005.

Petit, F.: Concepts d'analyse de la vulnérabilité des infrastructures essentielles: Prise en compte de la cybernétique, Dîplome de philosophiae doctor, Département des génies civil, géologique et des mines, Ecole Polytechnique de Montréal, Université de Montréal, Montréal, 267 pp., 2009.

Petit, F., Robert, B., and Rousselle, J.: Une nouvelle approche pour la caractérisation des aléas et l'évaluation des vulnérabilités des réseaux de support à la vie, Can. J. Civ. Eng., 31, 333-344, doi:10.1139/L04-008, 2004.
Popescu, C.-A. and Simion, C. P.: A method for defining critical infrastructures, Energy, 42, 32-34, 2011.

Rinaldi, S. M., Peerenboom, J. P., and Kelly, T. K.: Identifying, understanding, and analyzing critical infrastructure interdependencies, IEEE Control Syst. Mag., 21, 11-25, doi:10.1109/37.969131, 2001.

Robert, B.: Etude des risques et des effets domino produits par la défaillance d'un aménagement hydroélectrique, Congrès annuel de la Société canadienne de génie civil, Montréal, Québec, Canada, 10 pp., 2002.

Robert, B., Forget, S., and Rousselle, J.: The effectiveness of flood damage reduction measures in the montreal region, Nat. Hazards, 28, 367-385, 2003a.

Robert, B., Sabourin, J.-P., Glaus, M., Petit, F., and Senay, M.-H.: A new structural approach for the study of domino effects between life support networks, in: Building safer cities. The futur of disaster risk, edited by: Kreimer, A., Arnold, M., and Carlin, A., Disaster risk management series, The World Bank, Washington, DC, 245-272, 2003b.

Robert, B., Senay, M.-H., Plamondon, M.-È. P., and Sabourin, J.P.: Characterisation and ranking of links connecting life support networks, in, edited by: PSEPC (Public Safety and Emergency Preparedness Canada), Ottawa, 74 pp., 2003c.

Røstum, J., November, V., and Jørn, V.: Proactive crisis management of urban infrastructure, final scientific report of cost action c19, in: COST Urban Civil Engineering Transport and Urban Development Domain, European Science Fundation, 242 pp., 2008.

RTE: Mémento de la sûreté du système électrique, Réseau de Transport d'Electricité, Département Exploitation du Système Électrique, Paris, 2004.

Scawthorn, C., Blais, N., Seligson, H., Tate, E., Mifflin, E., Thomas, W., Murphy, J., and Jones, C.: Hazus-mh flood loss estimation methodology. I: Overview and flood hazard characterization, Nat. Hazards Rev., 7, 60-71, doi:10.1061/(ASCE)15276988(2006)7:2(60), 2006a.

Scawthorn, C., Flores, P., Blais, N., Seligson, H., Tate, E. Chang, S., Mifflin, E., Thomas, W., Murphy, J., Jones, C., and Lawrence, M.: Hazus-mh flood loss estimation methodology. Ii. Damage and loss assessment, Nat. Hazards Rev., 7, 72-81, doi:10.1061/(ASCE)1527-6988(2006)7:2(72), 2006b.

SETRA: Image de la qualité des ouvrages d'art: Classification des ouvrages, Service d'Etudes Techniques des Routes et Autoroutes, Bagneux, 30 pp. 1996a.

SETRA: Image de la qualité des ouvrages d'art: Catalogue des désordres. Les appuis et appareils d'appui, 40 pp., $1996 \mathrm{~b}$.

S.I.E.E.: Inondations du rhône et de ses principaux affluents de décembre 2003 en aval de viviers dans les départements de la drome, de l'ardèche, du gard, du vaucluse et des bouches du rhône, inventaire des zones inondées, des enjeux et des dégâts, 62 pp., 2005.

Smith, D. I.: Flood damage estimation - a review of urban stagedamage curves and loss functions, Water Sa., 20, 231-238, 1994.

SOGREAH and ASCONIT: Etude préalable à la réduction de la vulnérabilité des réseaux liée aux inondations en loire moyenne, Résultats, bilan et perspectives, Etablissement Publique Loire, Orléans, 178 pp., 2006.

Sohn, J.: Evaluating the significance of highway network links under the flood damage: An accessibility approach, Transp. Res. Part A: Policy Practice, 40, 491-506, 
doi:10.1016/j.tra.2005.08.006, 2006.

Thieken, A. H., Muller, M., Kreibich, H., and Merz, B.: Flood damage and influencing factors: New insights from the august 2002 flood in Germany, Water Resour. Res., 41, W12430, doi:10.1029/2005wr004177, 2005.

Utne, I. B., Hokstad, P., and Vatn, J.: A method for risk modeling of interdependencies in critical infrastructures, Reliab. Eng. Syst. Safety, 96, 671-678, 2010.

Vazquez, J., Zug, M., Phan, L., and Zobrist, C.: Guide technique sur le fonctionnement des déversoirs d'orage, 184 pp., 2006.

Vinet, F.: Crues et inondations dans la france méditerranéenne. Les crues torrentielles des 12 et 13 novembre 1999 (aude, tarn, pyrénées-orientales, hérault), Géographie des risques, edited by: Géographie, Q. d., Editions du temps, Nantes, 2003.
White, G. F.: Human adjustment to floods, Department of geography research papers, edited by: Chicago, U. o., University of Chicago, Chicago, 225 pp., 1945.

White, G. F.: Choice of adjustment to floods, Department of geography research papers, edited by: Chicago, U. o., University of Chicago, Chicago, 150 pp., 1964.

Winkler, J., Dueñas-Osorio, L., Stein, R., and Subramanian, D.: Performance assessment of topologically diverse power systems subjected to hurricane events, Reliab. Eng. Syst. Safety, 95, 323336, doi:10.1016/j.ress.2009.11.002, 2010. 